\title{
Academic Adjustment Issues in a Malaysian Research University: The Case of Cambodian, Laotian, Burmese, and Vietnamese Postgraduate Students' Experiences
}

\author{
Rany Sam ${ }^{1}$, Ahmad Nurulazam Md Zain ${ }^{2}$, Hazri Bin Jamil ${ }^{2}$, Thongma Souriyavongsa ${ }^{3} \&$ Le To Do Quyen ${ }^{4}$ \\ ${ }^{1}$ School of Educational Studies, Universiti Sains Malaysia and University of Battambang, Cambodia \\ ${ }^{2}$ School of Educational Studies and National Higher Education Research Institute, Universiti Sains Malaysia, \\ Penang, Malaysia \\ ${ }^{3}$ School of Educational Studies, Universiti Sains Malaysia and National University of Lao, Lao PDR \\ ${ }^{4}$ School of Social Science, Universiti Sains Malaysia and Ho Chi Minh University of Education, Vietnam \\ Correspondence: Rany Sam, School of Educational Studies, Universiti Sains Malaysia, 11800, Minden, Penang, \\ Malaysia. Tel: 60-175-063-234. E-mail: samrany82@yahoo.com
}

Received: June 24, 2013 Accepted: July 26, 2013 Online Published: August 16, 2013

doi:10.5539/ies.v6n9p13 URL: http://dx.doi.org/10.5539/ies.v6n9p13

\begin{abstract}
The Malaysian government aims to help the bottom billion countries, which are its neighbouring countries in the South East Asian region, for their human capital development through providing university postgraduate scholarship projects. Those countries include Cambodia, Laos PDR, Burma or Myanmar, and Vietnam (CLMV), which are favourite countries for its technical assistance. Due to the countries' various educational systems, postgraduate students have experienced some academic difficulties during their studies and research in Malaysian universities. A qualitative research method is employed to investigate students' living strategies, perception of academic success, and academic adjustment problems in a Malaysian university. Research samples were conducted conveniently selected from a total of 17 students made up of 6 Cambodian, 4 Laotian, 2 Myanmar, and 5 Vietnamese postgraduate students (47, 05\% females and 52, 94\% males) who have studied in the Universiti Sains Malaysia (USM) so called the Research University in the academic year 2012/2013, where they have attended the schools of educational studies, social science, and materials and mineral resource engineering. The result showed that the most difficult problem in term of academic adjustment which is English language difficulty in their new learning environment. In order to remedy such matters, they must strive to study hard, to improve English proficiency, and to make good relations with their academic staff, thesis supervisors, and other postgraduate students. In other words, social adjustment is considered as one of the important strategies that enable them to cope with the context of Malaysian culture. Based on the findings, the researchers provide recommendations to facilitate CLMV students to make better adjustments in a Malaysian research university and to achieve their academic endeavour.
\end{abstract}

Keyword: academic adjustment, CLMV postgraduate student, Malaysian tertiary institution

\section{Introduction}

\subsection{Scenario of International Students in Malaysian Universities}

International students are defined as individuals who move to a country differ from their country of citizenship in order to enrol in the foreign educational institutions (OECD, 2013). There were 2.5 million students who studied outside their home countries (UNESCO, 2009). The most preferred destinations of international students are the United States, United Kingdom, Germany, Australia and France (OECD, 2013). Among prestigious hubs of higher learning institutions in Asia, Malaysia is an excellent educational hub to import foreign students from Asian and African continents. They have decided to continue their higher education in Malaysian higher learning institutions for two main reasons. First, the majority of Malaysian universities uses English language as a medium of instruction at the undergraduate and graduate programmes. Second, Malaysia is a multicultural country with a mixture of Islamism, Buddhism, Hinduism, and Christianity. In addition, based on geographic location, Malaysia is close to South East, Middle East, and East Asian countries. As a result, international 
students' enrolment has dramatically increased and became Malaysia becomes the second most popular educational hub to host international scholars in the region following Singapore (World Education Service, 2007). According to QS World University Rankings (2013), Universiti Sains Malasia ranks number two amongst the top five Asian Universities for the number of international graduate students with 4499 international postgraduate students currently studying at this university, whereas the National University of Singapore (NUS) ranks number one with a total of 10,793 international postgraduate students.

Moreover, some international students have chosen Malaysia as their academic destination rather than the United States of America because of the security and terrorism consequences of September 11, 2001; they have sought places close to their countries (Morshidi, 2008). As a result, there were about 80,750 international students from 167 countries around the world enrolled in public and private higher learning institutions in Malaysia (MoHE, 2010). Most of them came from Iran (10,932 students), Indonesia (9,812 students), China (9,177 students), Nigeria (5,969 students) and Yemen (4,931 students) (MoE, 2010). According to the Ministry of Higher Education (2007), there were twenty public universities, thirty three private universities, four foreign university branch campuses, twenty four polytechnic schools, thirty seven public community colleges, and approximately 500 private colleges throughout the nation. There were five research universities in Malaysia such as Universiti Malaya (UM), Universiti Sains Malaysia (USM), Universiti Kebangsaan Malaysia (UKM), Universiti Putra Malaysia (UPM), and Universiti Teknologi Malaysia (UTM), (Singh, 2011).

In addition, there were a variety of international joint degree programs at both the undergraduate and postgraduate levels requiring cooperation between Malaysian higher educational institutions and foreign universities from the United Kingdom, the United States, Australia, Canada, France, Germany and New Zealand (MoHE, 2009). Most of the foreign students are enrolled in programs that relate to technology, information and communications technologies (ICTs) and business studies. To sum up, Malaysia is an excellent hub to import international students to study in its higher learning institutions for the country's economic growth. To support the expanding of enrolment rates, Malaysian universities need to examine the origins of such international students' problems in order to take effective measure to treat them.

\subsection{Scenario of CLMV Students at a Malaysian Research University}

Cambodia, Laos PDR, Myanmar, and Vietnam are located on the mainland of Southeast Asia, and their population was estimated around 15.2 million, 6.5 million, 55.1 million and 92.4 million people respectively (Central Intelligence Agency, 2013). Out of 187 countries in the world, Vietnam ranked $128^{\text {th }}$, Laos ranked $138^{\text {th }}$, Cambodia ranked $139^{\text {th }}$ and Myanmar ranked $149^{\text {th }}$ in term of human capital index (UNDP, 2011). None of CLMV universities are listed in the top 500 World Class University Ranking (QS University Ranking, 2013). There are fewer CLMV students enrolled in Malaysian higher educational institutions when compared to other countries because most students may have not the financial capacity for their tuition fees and living costs in this country based on the economic status and gross domestic products per capita of their home countries (World Bank, 2012). Without scholarships and financial support from their own countries, development agencies, and host universities, they cannot survive to succeed in their educational endeavours in Malaysia.

In other words, educational organizations are viewed as critical barriers to attract CLMV students. For example, the Malaysian educational system is based on the United Kingdom education system, whereas Cambodia, Lao, and Vietnam so-called Indochina countries, their educational background base on French and Russian educational systems. Conversely, Myanmar is influenced by the United States educational system in the past. In addition, admission requirements strictly recruit only qualified students based on high English proficiency test, scores of 6.0 in IELTS or scores of 550 in TOEFL (IPS, 2013). Seventeen participants in this study were scholarship and fellowship holders provided by the Southeast Asia Engineering Education Development Network and JICA, the Universiti Sains Malaysia-Vietnam International Education Development Joint Fellowship Scheme, and USM Fellowship Scheme.

In summary, CLMV countries which are categorized as bottom billion countries, graduate students from CLMV countries have challenged academic problems to succeed in their studies because of various educational and socioeconomic, lack of language proficiency, political and cultural background. Students should be well prepared and be cognizant of academic difficulties prior to pursuing their higher education in Malaysia.

\section{International Students' Academic Adjustment Problems}

Not surprisingly, it is undeniable that international students have experienced some troubles in term of varied academic system and educational atmosphere in the foreign countries. As freshmen, they must endeavour to learn a local language and to cope with an unpleasant situation as well as cultural shock. International students always suffer hardship problems if they are not familiar with a learning environment (Lin \& Yi, 1997). In a similar fashion, 
they bear the burden to adjust to the new academic system which requires them to make a best effort in order to succeed in their studies.

Numerous changes and obstacles have confronted international students, so they have to cope with academic pressures, various cultures, and language barriers in the United State education system (Zhai, L. 2004). Findings similar to those made by Church (1982) were confirmed by Tseng \& Newton (2002) whose study on international students' adjustment problems found that international students' academic difficulties resulted from language barrier, financial constraints, mental health problem, new educational adaptation, and new social regulation. Tseng \& Newton (2002) categorised adjustment problems into four main groups: namely academic adjustment, personal adjustment, religious accommodation, and financial adjustment. Other previous research also found that international students were having a myriad of difficult issues in adapting to a new educational situation as well as cultural experiences and in daily activities (Selvadurai, 1992; Wang, 2003; Cigularova, 2005; Khawaja \& Dempsey, 2007).

Andrade (2006) identified five vital conceptions reflecting the correlation between international students' academic difficulties and their educational attainment in the universities which used English as the medium of instruction. First, international students have encountered challenges with English language barrier and cultural shock that negatively impacted on academic and social adjustment such as anxiety, distress, tension, and loneliness; they rarely received social support when compared with local students. Second, international students may need various kinds of social support in accordance with their actual needs in the host countries and universities. Third, there has been a gradual progress in the adjustment process. Fourth, universities have often misinterpreted international students' personalities, and they have to deepen understanding of their difficult academic and psychological situations. Universities can reform teaching pedagogy in order to assist international students' learning needs. Lastly, international scholars, who have academic strategies such as study skills, tenacity, and motivation, usually attain academic success; they enjoy in their academic experiences in the foreign universities.

Most of the literature has been highlighted that English language proficiency is a common concern and problem of international students. Studies have found that international students may experience difficulty adapting to the different accents of the lecturers, pronunciation, instruction and examination because they need more time to understand their textbooks, journal articles etc. Additionally, they often are not able to convey their thoughts and academic writing because of their poor English proficiency (Lin and Yi, 1997; Ryan \& Twibell, 2000; Suseela, 2011). In short, international students have encountered several adjustment problems, but the most important is, English language difficulties, which affect their academic success. Therefore, international students should possess a high level of English language proficiency prior to pursuing their education in English speaking universities.

\section{Problem Statement}

Some researchers pointed out that a better adjustment has a positive effect on students' academic success (Tinto, 1993; Tamirie, 1997; Chong, et al., 2009). International students face common problems in adapting to the new learning environment in foreign countries such as general living adjustment (accommodation difficulties, dietary restriction, financial stress, misunderstandings); socio-cultural adjustment (racial discrimination, intercultural communication, and religions), and personal psychological adjustment (loneliness, homesickness, and stresses) and academic adjustment- new educational system and language problems (Lin and Yi, 1997; Tseng \& Newton, 2002).

Similarly, CLMV postgraduate students also encounter such adjustment problems like other international students can affect their academic performance. In other words, academic adjustment is one of the most difficult problems faced by them. As the result, the researchers have mainly focused on it while other adjustments are not included in this study because CLMV students found that they adjusted to Malaysian context. Therefore, Malaysian universities should pay more attention to understand international postgraduate students' academic difficulties and to provide necessary academic support services to handle these problems.

\section{Research Objectives}

It was designed for the following objectives:

- To examine the living strategy of postgraduate students in order to achieve their academic endeavours.

- To investigate the postgraduate students' perception of academic success; and

- To investigate postgraduate students experience of academic adjustment problems in their new learning environment in Malaysia. 


\section{Research Questions}

In order to achieve the purpose of this study, three questions were developed:

- What are the strategies of CLMV postgraduate students for living in Malaysia?

- How do postgraduate students perceive academic success?

- What are the academic adjustment issues experienced by CLMV postgraduate students enrolled in a Malaysian university?

\section{Research Methodology}

\subsection{Population and Sampling Procedure}

In the study, seventeen postgraduate students, which included eight females and nine males (Table 1), participated in this study. The researchers used the convenient sampling method to select these samples, participants comprised of 6 Cambodians, 4 Laotians, 2 Burmese, and 5 Vietnamese students (47, 05\% Females and 52, 94\% males), who have studied in the Universiti Sains Malaysia. Their ages were between 25 and 34 years at the time of research, and the length of residency in Malaysia ranged from 13 months to 60 months. Twelve participants were attending $\mathrm{PhD}$ programs, and other five participants were pursuing their master degree by research. They were receiving financial support from the ASEAN University Network and the Southeast Asia Engineering Education Development Network- JICA project (AUN/SEED-Net), Universiti Sains Malaysia-Vietnam International Education Development Joint Fellowship Scheme (USM-VIED), and USM Fellowship Scheme.

Table 1. Demographics of participants

\begin{tabular}{llllll}
\hline Code & Age & Sex & $\begin{array}{l}\text { Length of stay in } \\
\text { Malaysia (Months) }\end{array}$ & Course Mode & $\begin{array}{l}\text { Previous } \\
\text { occupation in } \\
\text { their countries }\end{array}$ \\
\hline P1 & 32 & Female & 60 & PhD & Lecturer \\
P2 & 30 & Female & 13 & Master by Research & Researcher \\
P3 & 25 & Female & 20 & Master by Research & Lecturer \\
P4 & 29 & Female & 60 & PhD & Researcher \\
P5 & 28 & Female & 60 & PhD & Researcher \\
P6 & 28 & Female & 39 & PhD & Lecturer \\
P7 & 29 & Female & 34 & PhD & Lecturer \\
P8 & 32 & Female & 60 & PhD & Lecturer \\
P9 & 30 & Male & 36 & PhD & Lecturer \\
P10 & 35 & Male & 72 & PhD & Researcher \\
P11 & 32 & Male & 72 & PhD & Lecturer \\
P12 & 25 & Male & 13 & Master by Research & Researcher \\
P13 & 26 & Male & 17 & Master by Research & Researcher \\
P14 & 32 & Male & 20 & PhD & Lecturer \\
P15 & 33 & Male & 25 & Master by Research & Researcher \\
P16 & 34 & Male & 30 & PhD & Lecturer \\
P17 & 33 & Male & 24 & PhD & Tutor \\
\hline
\end{tabular}

Note: $\mathrm{P}=$ Participant

\subsection{Research Method}

The researchers used a qualitative research approach as a thematic analysis procedure that allowed the researchers to identify and to report the themes in the data analysis. This method is widely used in psychometric 
research (Braun \& Clarke, 2006). The data were collected from the participants using semi-structured interview which last approximately 30 minutes, and the participants freely answered their opinions and experiences.

The researchers read interview transcripts several times in order to get the relevant information and to summarize them based on participants' responses. The six steps of the thematic analysis procedure are: (1) familiarizing with the data, (2) generating initial codes, (3) searching for themes, (4) reviewing themes, (5) defining and naming themes, and (6) producing the report (Braun \& Clarke, 2006; Renee and Jill, 2013).

\section{Finding and Discussion}

\subsection{Research Question One}

What are the strategies of CLMV postgraduate students for living in Malaysia?

The results of the investigation reveal that the majority of CVLM postgraduate students were optimistic, wellorganized, persistent, and well-focused on their studies. This attitude is considered as an effective strategy to succeed in their academic performance in Malaysian context. Because of time constraints, all postgraduate students have excelled in their research plan and thesis writing to finish their studies within the time frame provided by the scholarship projects. After graduating, they will return to serve their home countries in private and public sectors as well as in higher education institutions and research centres in particular. One of the respondents explained his experiences that:

"Every day, I study in my school's PhD room from morning until midnight, and I have to complete my works advised by my thesis supervisors. I see them regularly at least two times per month; I am delighted to learn new knowledge and to acquire new skills at my university. Even though I am stressed with my research progress, I have to work hard in order to graduate on time according to my scholarship project and research plans (P4)".

The major finding of the research is that CLMV postgraduate students have set up new networks among friends, classmates, lecturers, and executive programs. These networks have strengthened their mutual relationship and help them to heal mental health problems namely stresses, loneliness, and nostalgia. They have sought support from friends, lecturers, and supervisors on how to begin their academic works on the right track. For example, one participant shared that she has established a good relationship with her supervisors and Malaysian students. As a result, she received encouragement and assistance to help her to complete her $\mathrm{PhD}$ thesis writing on a proposed plan.

The findings of this research are consistent with those of Harman (2003) and Poyrazli \& Grahame (2007) who found that faculty members, academic staff, and local and international $\mathrm{PhD}$ students provide social and academic support to assist graduate students to academic success. Additionally, one of the significant findings which emerges from this study is that CVLM postgraduate students have easily changed their daily habit and attitude in adapting to new regulations and lives in a Malaysian university. They are also actively involved in social events, and organizations including schools' postgraduate student associations, student associations of their own citizenships in Malaysia etc. For instance, they always get together with their friends from the same countries, other countries, and local friends as well. Most importantly, they frequently use phone calls and Facebook as a popular means of social communication to constantly contact their friends and families in Malaysia and the home countries. One respondent shared that:

"As a postgraduate student, I found that it was difficult to adapt to a new environment in USM. However, I find out how to modify my daily routine to comply with university's regulation. As a result, I manage to stay in the hostel even if it is a single or shared room, and I can use a bicycle to commute between the school and hostel. I have fulfilled the school's duties that required by fellowship conditions; I have to annually produce two academic articles for my fellowship extension. I also manage my stress and time. So, I manage to survive in Penang, Malaysia (P16)"'.

The most obvious findings that emerged from this study is that the majority of CLMV students believes in Buddhism, which considered as a living strategy of spiritual support for them in Malaysia. They always practice the teaching of the Buddha on how to live peacefully with others without the discrimination of religious belief, races, social classes, and political tendencies. In the interview, participants reported that religious preaching of the Buddha, which is self-reliance, help them to live independently and to overcome their academic tension. One of the participants shared that:

"Being a Buddhist, I always practice the precept of my religion so that I can handle those issues peacefully when I have faced hardship problems. Frankly, I found that faith is very important to help me to struggle with academic difficulties and to heal me whenever I have encountered stress, hopelessness, and loneliness in Malaysia (P13)." 
The present finding seems to be consistent with other research findings that religious figures have a significant role to provide a general mental and physical support when needed (Rowatt \& Kirpatrick, 2002; Sim \& Loh, 2003; Granqvist \& Kirkpatrick, 2008). Likewise, in a study carried out by Boktik \& Everall (2007) about healing from suicide revealed that religious belief provides spiritual and social support to heal people by avoiding suicidal thoughts. In essence, there were several living strategies that postgraduate students employed such as philosophical optimism, self-reliance, persistence, good discipline, flexibility, and good communication. These strategies can help students to better adapt to the new learning environment in a Malaysian university.

\subsection{Research Question Two}

\section{How do postgraduate students perceive on academic success?}

It was uncovered by the study that CLMV postgraduate students are optimistic in regards to the term academic success which they have based on their personal perception and experiences. Most participants reported that they were on the right path to achieve their academic endeavour, and such positive ideas would be helpful to motivate them to succeed in their postgraduate studies in Malaysia. For them, academic success means academic competencies that enable them to pass all compulsory courses, to produce many papers for prestigious academic journals, and to graduate on time. One participant shared that:

"To me, graduating on time with qualified knowledge and experiences is considered as my academic success. To achieve this goal, I have to work hard and effectively as well as to prepare a clear plan for my study and follow the advice of my supervisors. Passion and commitment enable me to achieve academic success because they encourage me to contend with these academic difficulties. Broadly speaking, I could say that I set off to conduct my research on right direction, so my research was completed according to my proposed timeline. (P5)".

The research has shown that postgraduate students have perceived that academic success is an academic achievement that enables them to produce a higher position, job promotion, and great prospective career in private and public sectors. Moreover, they have understood how to utilize their own strategies to be qualified and successful during their postgraduate studies in Malaysia. One participant reported that:

"In my opinion, academic success is a significant factor in providing me a golden opportunity to get a well-paid job and suitable position. I am confident that professional skills and expertise, which I acquired from the university, will help me to succeed in my current and future business. In order to realize my dream, I have to improve my personal development skills and other soft skills through attending many workshops and conferences that are organized by the university in order to challenge in my prospective labour market (P13)".

Overall, CLMV postgraduate students have a different perception of the term of academic success in their graduate studies. Understanding this concept may guide them in determining the best strategies to cope with their new learning environment in Malaysia and to overcome academic difficulties as well as to resolve other adjustment problems effectively.

\subsection{Research Question Three}

\section{What are the academic adjustment issues experienced by CLMV postgraduate students enrolled in a Malaysian university?}

The outcome of this study indicates that CLMV postgraduate students encountered challenges academic adjustment in three main areas which include: (1) an unfamiliar educational system, (2) English language barrier, and (3) supervisors and student relationship. These effects may be explained by the fact that unfamiliarity with an academic system can cause students to suffer some problems within their new learning environment in the foreign countries. Some participants reported that the academic system in Cambodia, Laos, and Vietnam are quite different from Malaysia. Malaysian system is more focused on practical experience in the laboratory and industrial training pedagogy as well. It is more student-centred in its teaching methodology, and research characteristics, while the educational systems of three countries mainly involve in more theories, with teacher-centred methods, and of a non-research nature. In addition, there is a choice of study modes in graduate programmes in a Malaysian research university: coursework, mixed-mode (a combination of coursework and research), and research (Master by research and PhD) (IPS, 2013a).

One Vietnamese participant reported that the academic grading practice in her country differs from that of Malaysia's. For example, the Vietnamese grading system is based on 1-10 point scale, whereas the Malaysian is based on 1.0 to 4.0 scale. Accordingly, she had difficulties to adapt to this grading system, but she learned that she had to struggle and to succeed in this new academic system. Similarly, some Cambodian higher learning institutions grade on a 1-20 point scale, but the others grade on the United States so called credit grading system, which grades from 1.0 to 4.0 (Grade Point Average). One participant from Laos PDR shared that he found it 
difficult to familiarize himself with postgraduate programmes in Malaysia because university programmes do not offer any compulsory courses to support his research. As a $\mathrm{PhD}$ student, he was required to study independently and to attend many workshops and conferences to develop his research competency; he stated that because he did his Master's degree by coursework in his country he was weak in research skill and academic writing; therefore he needed some necessary skills and experiences in order to adjust himself to this educational system.

Another major finding of this study is that lack of English language skills is the most difficult problem for Cambodian, Laotian, Manama (Burmese), and Vietnamese students because they have always used their own languages as the medium of instruction in their own countries. English is a foreign language of CLMV postgraduate students, so they have to adapt to a Malaysian university system which uses the English language as the medium of instruction and learning. Some participants who came from Cambodia, Laos, and Vietnam reported that they have used the French language to acquire their first and second degrees from universities in cooperation with and supported by France, so it was difficult for them to learn another foreign language like English in a Malaysian university. Certainly, most of the participants reported that because they have great difficulties in English reading and writing they had to spend a lot of times to read academic journals, textbooks, and other documents for their Master and $\mathrm{PhD}$ dissertation writing. This language barrier affected CLMV postgraduate students' research progress to graduate on time. For example, one student said that he wasted much time to understand academic papers and textbooks because of his limited understanding of English terminologies, grammar, and structure. He often spent two or three days for each page of thesis writing due to the weakness of his English academic writing skills such as paraphrasing, synthesising, and critically reviewing related literature etc.

Furthermore, one participant reported that she was unable to communicate with her supervisors and postgraduate friends because of poor English language skills. She tried to improve her English language skills through practicing with her friends, attending in English classes, participating in a group meeting and establishing a good relationship with other peers. The outcome of this study seemed to corroborate the findings of the studies by Lin and Yi (1997); Ryan \& Twibell (2000); Adrade (2006); Poyrazli \& Grahame (2007); Kwon (2009); Suseela (2011) which identified that English language skills are the most significant skill for international students' academic success.

Last finding related to academic difficulties faced by CLMV postgraduate students showed that some students have problems in term of relationship with their supervisors because of supervisory time constraints and lack of right track supervisory structures. One participant reported that his research progress was very slow because of his educational background and supervisor's sabbatical leave and health problems. He spent nearly three years as a full time student in the university, before he could present his research proposal. He didn't want to complain about his supervisor because he understood his supervisor's problems and school's policies. He anticipated that his supervisors would provide him with more academic support and appropriate supervision in order to facilitate his journey in acquiring his doctorate degree. This finding agrees with Harman's (2003) findings which showed that Asian international students have some challenges with their thesis supervisors because of cultural and supervisory styles. Most students are afraid of the supervisors in the case of intercultural communication and interaction, so they hope that supervisors become useful guides to benefit them with qualified and effective academic supervision. These findings are consistent with the result of other researchers (Novera, 2004; Poyrazil \& Kavanaugh, 2006; Suseela \& Poovaikarasi, 2011), indicating that international students encounter great challenges to adjust to their new learning environment in foreign countries especially in English speaking universities in the world.

\subsection{Limitations}

There are several limitations to this study. One of the limitations of the research is the population of the study. This finding cannot be generalized because the samples were selected from one university, and the participants are adapting to a specific context in Malaysia. Second, the study mainly focuses on living strategies and academic adjustment, which are the most obvious problems experienced by students, whereas other adjustments such as financial adjustment, social adjustment, religious adjustment, and personal adjustment are not included in this study because CLMV postgraduate students can adjust well in the Malaysian context. Lastly, the limitation of the study is the reliability and validity of information and responses which arise if the participants did not entirely understand the interview questions; they cannot share their academic experiences and perceptions on the questions because of their lack of English proficiency. 


\section{Conclusion and Recommendation}

\subsection{Conclusion}

This research investigates academic experiences of CLMV postgraduate students in Malaysia. The qualitative research method was employed to interview 17 postgraduate students who have studied in the Universiti Sains Malaysia. As mentioned earlier in research objectives, the purpose of study was to investigate the living strategies, perception of academic success, and academic adjustment problems of CLMV postgraduate students in a Malaysian research university. The following conclusions can be drawn from the study showing that CLMV students have their own strategies such as optimism, persistence, networking, and a reliance on religious faith to adapt to the new learning atmospheres in Malaysia; they have perceived positively in the righteous ways they afforded for overcoming their academic tension in order to conquer these obstacles and succeed in their academic endeavour. The majority of postgraduate students has challenges in their academic difficulties because of a lack of the English language proficiency and unfamiliarity with the academic system in a Malaysian research university.

The results of the study also indicate that providing academic support for CLMV students will help them to maintain their academic performances and to adjust better in Malaysian context. In realizing this academic success, CLMV students have to establish more interaction with their thesis supervisors, academic staff, and other students as well as to improve their English four macro skills of academic writing, reading, listening, and speaking for their prospective academic careers and other jobs.

\subsection{Recommendation}

Based on the findings of the study, it is suggested that USM intensifies program to help foreign students to cope with whatever problems they are confronted during their studies. The following activities are suggested:

First, university, academic staff, and thesis supervisors should help CLMV postgraduate students to cope with a Malaysian educational system such as explaining the grading system, providing tutorials, and other academic activities. Second, universities should encourage academic and non-academic staff to deepen their understanding of the various backgrounds of international students. Additionally, supervisors should have more interaction and honest relationship with supervisees in order to facilitate them to graduate on times and to achieve a better academic result. Third, university should increase the provision of personal development courses, academic workshops and conferences for improving students' research capacity building and English academic writing so that the students can cope with any academic matters. In other words, students should improve their English language by attending language courses and developing relationship with other international students to build confidence to use English fluently. The last, Malaysian university should ensure that the fellowships offered do not require students to fulfil school's duties, publication requirement, and annual extension of the scholarship because these put more pressures on students who have to concentrate on their studies. Furthermore, university, development partners and scholarship agencies should provide more academic and non-academic support, so they can graduate on time on time and go back home to develop their countries.

\section{Acknowledgement}

First, we would like to express our thanks to Prof. Dr. Abdul Rashid Mohamed, Dean of School of Educational Studies for his support and encouragement. Second, we are also grateful to Cambodian, Laotiant, Myanmar, and Vietnamese postgraduate students who voluntarily participated in this study. Third, we also would like to thank Prof. Dr. Muhamad Jantan, Dean of the Institute of Postgraduate Studies, for his approval of fellowship extension. This study was supported by the USM PhD Fellowship Scheme of the Institute of Postgraduate Studies (IPS) at the Universiti Sains Malaysia. Last but not the least, the authors would like to express our thanks to Sister Lau Margaret for her English proofreading and editing in this manuscript.

\section{References}

Andrade, M. S. (2006). International Students in English-Speaking Universities: Adjustment Factors. Journal of Research in International Education, 5(2), 131-154.

Boktik, K., \& Everall, R., (2007). Healing from suicide: adolescent perceptions of attachment relationships. British Journal of Guidance and Counselling, 351(1), 79-96.

Braun, V., \& Clarke, V. (2006). Using Thematic Analysis in Psychology. Qualitative Research in Psychology, 3(2), 77-101. http://dx.doi.org/10.1191/1478088706qp063oa

Central Intelligence Agency. (2013). World Population. Retrieved June 12, 2013, from https://www.cia.gov/library/publications//the-world-factbook/rankorder/2119rank.html 
Chong, M. A., Elias, H., Mahayuddin, R., \& Uli, J. (2009). Adjustment among first year students in Malaysian University. European Journal of Social Sciences, 8(3), 496-505.

Church, A. (1982). Sojourner Adjustment. Psychological Bulletin, 91, 540-572.

Cigularova, D. K. (2005). Psychosocial Adjustment of International Students. Colorado State University Journal of Student Affairs, 14.

Granqvist, P., \& Kirkpatrick, L. A. (2008). Attachment and religious representations and behaviour. Handbook of attachement theory and research, 906-933.

Harman, G. (2003). International PhD students in Australian universities: financial support, course experience and career plans. International Journal of Educational Development, 23(3), 339-351.

IPS. (2013). Language Requirement of Institute of Postgraduate Studies Retrieved June 6, 2013, from http://www.ips. usm.my/index.php/ prospectiveStudents/ admission/ language requirement

IPS. (2013a). Postgraduate Program. Retrieved June 10, 2013, from http://www.ips.usm.my/index.php/programme

Khawaja, N. G., \& Dempsey, J. (2007). Psychological distress in international university students: An Australian study. Australian Journal of Guidance and Counselling, 17(1), 13-27.

Kwon, Y. (2009). Factors affecting international students' transition to higher education institutions in the United States: From the perspective of the office of international students. College Student Journal, 43(3), 1020-1037

Lin, J. C., \& Yi, J. K. (1997). Asian International Students' Adjustment: Issue and Program Suggestions. Journal of Multicultural Counselling and Development, 19(1), 173-178.

MoE. (2010). Perangkaan Pengajian Tinggi Malaysia: 2009. Kuala Lumpur, Ministry of Higher Education.

MoHE. (2007). The national higher education strategic plan: Laying the foundation beyond 2020. Kuala Lumpur, Ministry of Higher Education.

MoHE. (2009). Compilation of statistics. Putrajaya, Malaysia: Author.

Morshidi, S. (2008). The Impact of September 11 on International Student Flow into Malaysia: Lessons Learned, International Journal of Asia Pacific Studies, 4(1), 79-95.

Novera, I. A. (2004). Indonesian postgraduate student studying in Australia: An examination of their academic, social and cultural differences. International Education Journal, 5(4).

Organization of Economic Cooperation and Development (OECD). (2013). Definition of International Student. Retrieved June 1, 2013, from http://en.wikipedia.org/wiki/International_student

Poyrazli, S., \& Grahame, K. M. (2007). Barrier to adjustment: Needs of international students within a semi-urban campus community. Journal of Instructional Psychology, 33(3), 217-222.

Poyrazli, S., \& Kavanaugh, P. R. (2006). Marital Status, Ethnicity, Academic Achievement, and Adjustment Strains: The Case of Graduate International Students. College Student Journal, 40(4), 767-708.

QS University Ranking. (2012). World University Ranking. Retrieved June 10, 2013, from http://www.topuniversities.com/university-rankings/world-university-rankings/2012

QS University Ranking. (2013). Top Universities in Asia. Retrieved June 11, 2013, from topuniversities.com/asiarankings@worlduniversityranking@topunis\#QSWUR

Renee, \& Jill. (2013). How to use thematic analysis. Retrieved June 10, 2013, from https://sites.google.com/site/howtousethematicanalysis/home/how-to-use-thematic-analysis

Rowatt, W. C., \& Kirpatrick, L. A. (2002). Two dimensions of attachments to God and their relation to affect, religiosity, and personal constructs. Journal for the Scientific Study of Religion, 41(4), 637-651.

Ryan, M. E., \& Twibell, R. S. (2000). Concerns, values, stress, coping, health and educational outcomes of college students who studies abroad. International Journal of Intercultural Relations, 24(4), 409-435.

Selvadurai, R. (1992). Problems Faced by International Students in American Colleges and Universities. Community review.

Sim, T. N., \& Loh, B. S. M. (2003). Attachment to the God: Measurement and dynamics. Journal of Social and Personal relationship, 20(3), 373. 
Singh, V., Zain, A., \& Jamil, H. (2011). Establishment of International Policies to Support the Internationalization Process: The Case of Malaysian Research Universities. International Journal of Humanities and Social Science, 1(8), 130-139.

Suseela, M., \& Poovaikarasi, S. (2011). Adjustment problems among international students in Malaysian private higher education institutions. Procedia Social and Behavioural Sciences, 15(2011), 833-837.

Tamirie, A. (1997). Attributions and academic achievement of Education, Medicine and Poly Technique freshmen students in Bahir Dar. The Ethiopian Journal of Education, 17(2), 59-77.

Tinto, V. (1993). Leaving college: Rethinking the Causes and Cures of Student Attribution (2nd ed.). Chicago: University of Chicago Press.

Tseng, W. C., \& Newton, F. B. (2002). International students' strategies for well-being. College Student Journal, $36(4)$.

UNDP. (2011). Human Capital Implications of Future Economic Growth in Cambodia: Elements of a Suggested Roadmap. Phnom Penh, Cambodia: United Nation Development Program and Supreme National Economic Council.

United Nations for Development Program. (2011). Human Capital Implications of Future Economic Growth in Cambodia: Elements of a Suggested Roadmap. Phnom Penh, Cambodia: United Nation Development Program and Supreme National Economic Council. Retrieved June 6, 2013, from http://www.un.org.kh/index.php? option $=c_{-}$jdown loads\&Itemid $=65 \& v i e w=$ viewdownload \& catid $=4 \& \mathrm{cid}=84$

Wang, J. (2003). A study of the adjustment of international graduate students at American universities, including both resilience characteristics and traditional backgrounds factors. The Florida State University, U.S.

World Bank. (2012). Gross Domestic Products Per Capita. Retrieved June 12, 2013, from http://data.worldbank.org/indicator/NY.GDP.PCAP.CD

World Education Service. (2007). International Student Mobility: Patterns and Trends.

Zai, L. (2004). Studying international students: adjustment issues and social support. Journal of International Agricultural and Extension Education, 11(1), 97-104.

\section{Copyrights}

Copyright for this article is retained by the author(s), with first publication rights granted to the journal.

This is an open-access article distributed under the terms and conditions of the Creative Commons Attribution license (http://creativecommons.org/licenses/by/3.0/). 